\title{
Detailed Comparison of Basal and Food-stimulated Gastric Acid Secretion Rates and Serum Gastrin Concentrations in Duodenal Ulcer Patients and Normal Subjects
}

\author{
A. John Blair III, Mark Feldman, Cora Barnett, John H. Walsh, and Charles T. Richardson \\ Departments of Internal Medicine and Surgery, Veterans Administration Medical Center and University of Texas Southwestern Medical \\ School, Dallas, Texas 75216; and Veterans Administration Medical Center and University of California Medical School, \\ Los Angeles, California 90073
}

\begin{abstract}
We measured basal and peak acid outputs, food-stimulated acid secretion, and basal and food-stimulated serum gastrin concentrations in a large group of duodenal ulcer patients and normal subjects. Basal and peak acid outputs were significantly higher in ulcer patients. In contrast, acid secretion was similar in the groups when food was infused into the stomach and when sham feeding was combined with meal infusion to simulate normal eating. Meal-stimulated acid secretion, expressed as a percentage of peak acid output to correct for differences in secretory capacity, was lower in ulcer patients $(P<\mathbf{0 . 0 0 2})$. Basal serum gastrin concentrations were higher in ulcer patients, which may have contributed to higher basal acid output. However, increases in serum gastrin after food were similar in the groups. Duodenal ulcer patients, as a group, have increased basal and maximal acid secretion, but the amount of acid secreted and gastrin released after eating is normal.
\end{abstract}

\section{Introduction}

Mean basal (BAO) ${ }^{1}$ and peak acid outputs (PAO) consistently have been reported to be increased in patients with duodenal ulcer (DU) disease (1). In contrast, there has been no concensus as to whether food-stimulated acid secretion is also increased in DU patients (2). Results of some studies in relatively small groups of patients and controls have suggested that food-stimulated acid secretion is higher in DU patients than in normal subjects (35 ), although other investigators have been unable to confirm this $(6,7)$. The present experiments were designed to compare food-stimulated acid secretion in much larger groups of DU patients and normal subjects than have been reported previously. Because gastrin is the major mediator of food-stimulated acid secretion $(8,9)$, serum gastrin concentrations were measured as well. BAO and PAO also were determined in each patient and subject for comparison.

Part of this work was published in abstract form (1984. Gastroenterology. 86:1219) and was presented at the American Gastroenterological Association meeting in New Orleans, LA on 23 May 1984.

Address reprint requests to Dr. Richardson, VA Medical Center (11), 4500 South Lancaster Road, Dallas, TX 75216.

Received for publication 20 June 1986 and in revised form 16 September 1986.

1. Abbreviations used in this paper: BAO, basal acid output; DU, duodenal ulcer; PAO, peak acid output.

The Journal of Clinical Investigation, Inc.

Volume 79, February 1987, 582-587

\section{Methods}

Studies were approved by a Human Research Review Committee and all participants gave written informed consent prior to inclusion in these experiments.

\section{Ulcer patients and normal subjects}

In this study 58 patients with chronic, inactive DU (50 male) and 91 normal subjects (65 male) participated. Mean age was 46 yr (range 22$75 \mathrm{yr}$ ) in the DU group and $30 \mathrm{yr}$ (range 19-50 yr) in the control group. Antisecretory medications were discontinued for $48 \mathrm{~h}$ before each study in DU patients. All experiments were carried out after patients and subjects had fasted for at least $12 \mathrm{~h}$ overnight. The next morning, a nasogastric tube (AN 10, H. W. Andersen Products, Inc., Oyster Bay, NY) was swallowed and then positioned in the dependent portion of the stomach under fluoroscopic guidance.

\section{Basal and peak acid output}

In each patient and subject, BAO was measured for $1 \mathrm{~h}$, followed by measurement of PAO for $1 \mathrm{~h}$ in response to a subcutaneous injection of $6 \mu \mathrm{g} / \mathrm{kg}$ pentagastrin or $40 \mu \mathrm{g} / \mathrm{kg}$ histamine acid phosphate (10). Samples of gastric juice were collected by aspiration (Stedman Suction Pump, American Cystoscope Makers, Inc., Stamford, CT), with suction applied for 48 out of $60 \mathrm{~s}$. Each sample of gastric juice was collected for $15 \mathrm{~min}$. The volume was measured and hydrogen ion concentration was determined by glass electrode (11). Acid output was calculated by multiplying volume in liters times hydrogen ion concentration in millimoles. BAO was defined as the sum of the four 15-min acid outputs during the first hour, whereas PAO was defined as the sum of the two highest consecutive 15-min outputs during the second hour, multiplied by 2 to express results in $\mathrm{mmol} / \mathrm{h}$.

\section{Meal-stimulated acid secretion and serum gastrin}

Four sets of experiments were carried out to compare meal-stimulated acid secretion and/or gastrin release in DU patients and normal controls.

Experiment 1. This experiment was designed to compare food-stimulated acid secretion and serum gastrin concentration for $2 \mathrm{~h}$ after a meal in a large group of DU patients and normal subjects (54 DU patients, 79 normal subjects). The meal used to stimulate acid secretion and gastrin release consisted of $142 \mathrm{~g}$ of ground, lean, cooked sirloin steak, $28 \mathrm{~g}$ of bread, and $5 \mathrm{~g}$ of butter. This meal contained $305 \mathrm{cal}$ with $25.0 \mathrm{~g}$ of protein, $8.7 \mathrm{~g}$ of carbohydrate, and $17.8 \mathrm{~g}$ of fat. The meal was cooked, homogenized in a Waring Blendor (Waring Products Division, New Hartford, CT), adjusted to $\mathrm{pH} 5.0$ by adding $10-20 \mathrm{ml}$ of $0.3 \mathrm{~N} \mathrm{HCl}$ and then adjusted to a final volume of $600 \mathrm{ml}$ by adding water. The blended steak meal was then infused into the stomach through the nasogastric tube. Acid secretion was measured for $2 \mathrm{~h}$ by in vivo intragastric titration with sodium bicarbonate to $\mathrm{pH} 5.0$ (3), which was infused into the stomach through a polyvinyl tube glued to the nasogastric tube. Peak acid secretion rates after the meal were defined as the sum of the two highest consecutive 15-min acid secretion rates, multiplied by 2 to express results in millimoles per hour.

Experiment 2. In experiment 1 acid secretion was measured in response to a meal which was infused directly into the stomach through 
the nasogastric tube, bypassing the cephalic phase of acid secretion. Experiment 2 was designed to simulate normal eating, evaluating the effect of all three phases of food-stimulated acid secretion (cephalic, gastric, and intestinal phases) (12). As described above, a blended steak meal was infused through a nasogastric tube. In addition, sham feeding, using a chew-and-spit technique (12), was carried out during the initial 30min period after intragastric meal infusion. The meal used for sham feeding consisted of $227 \mathrm{~g}$ of sirloin steak, $142 \mathrm{~g}$ of french-fried potatoes, and $300 \mathrm{ml}$ of water. As in experiment 1 , acid secretion was measured for $2 \mathrm{~h}$ by in vivo intragastric titration to $\mathrm{pH}$ 5.0. $19 \mathrm{DU}$ patients and 21 normal subjects participated in this experiment.

Experiment 3. In the first two experiments, the acid secretory response to the meal was still in progress at the termination of the $2 \mathrm{~h}$ experiment (see Results below). Experiment 3 was designed to follow the acid secretory response to the meal for $5 \mathrm{~h}$. BAO was measured for $1 \mathrm{~h}$ as described above and then a meal identical to that in experiment 1 and 2 was infused through a nasogastric tube. Acid secretion was measured by in vivo intragastric titration to $\mathrm{pH} 5.0$ for the first $3 \mathrm{~h}$ after the meal. At the end of $3 \mathrm{~h}$, measurement of acid secretion by in vivo titration becomes technically difficult because most of the meal has emptied from the stomach and intragastric volume is small, making it difficult to obtain frequent gastric juice samples and to titrate accurately. Therefore, gastric contents were emptied by aspiration $3 \mathrm{~h}$ after the meal; then acid secretion was measured by aspiration during the fourth and fifth postprandial hours (10). 15 DU patients and 15 normal subjects participated.

Experiment 4. In a final series of experiments, we compared serum gastrin concentrations before and for $2 \mathrm{~h}$ after a normally eaten meal in 15 DU patients and 15 normal subjects. The meal was identical to the meal that was homogenized and then infused into the stomach in experiments 1-3. All patients finished eating the meal within $15 \mathrm{~min}$. In these studies, subjects and patients were not intubated and no attempt was made to measure acid secretion or to control intragastric pH at 5.0.

\section{Measurement of serum gastrin}

Blood samples were obtained at times indicated in Results through an indwelling catheter, which was placed in a forearm vein and kept open by slow infusion of $0.15 \mathrm{M} \mathrm{NaCl}$. Coded sera were shipped from Dallas to Los Angeles on dry ice for gastrin assay. Serum gastrin concentrations, measured using C-terminal-directed antibodies equally reactive to little gastrins (G-17) and big gastrins G-34 (13), were expressed in picograms per milliliter. Because of the large number of specimens in experiments 1 and 2, samples for gastrin measurement were not run together in the same assay. On the other hand, all sera from DU patients and controls in experiment 3 were assayed together, as were all serum samples from experiment 4 .

\section{Statistical methods}

Results are expressed as mean \pm 1 SEM. Differences between DU patients and controls were tested by two-tailed group $t$ test, with $P$ values $<0.05$ considered significant. Correlation coefficients were calculated by linear regression analysis. Average serum gastrin rises above basal serum gastrin concentrations after the meals were calculated by dividing the integrated gastrin response by $2 \mathrm{~h}$ in experiments 1,2 , and 4 and by $5 \mathrm{~h}$ in experiment 3 (14)

\section{Results}

\section{Basal and peak acid output}

As shown in Fig. 1 (top), mean BAO was approximately twice as high in the $58 \mathrm{DU}$ patients as in the 91 normal subjects ( $7.1 \pm 0.7$ vs. $3.3 \pm 0.4 \mathrm{mmol} / \mathrm{h}, P<0.001)$. As indicated in Fig. 1 (middle), mean PAO was also considerably higher in the DU group than controls $(50.8 \pm 2.2$ vs. $36.3 \pm 1.4 \mathrm{mmol} / \mathrm{h}, P<0.001)$. BAO averaged $14 \pm 1 \%$ of PAO in DU patients vs. $9 \pm 1 \%$ of PAO in normal subjects $(P<0.005)$ (Fig. 1 , bottom). There was con-
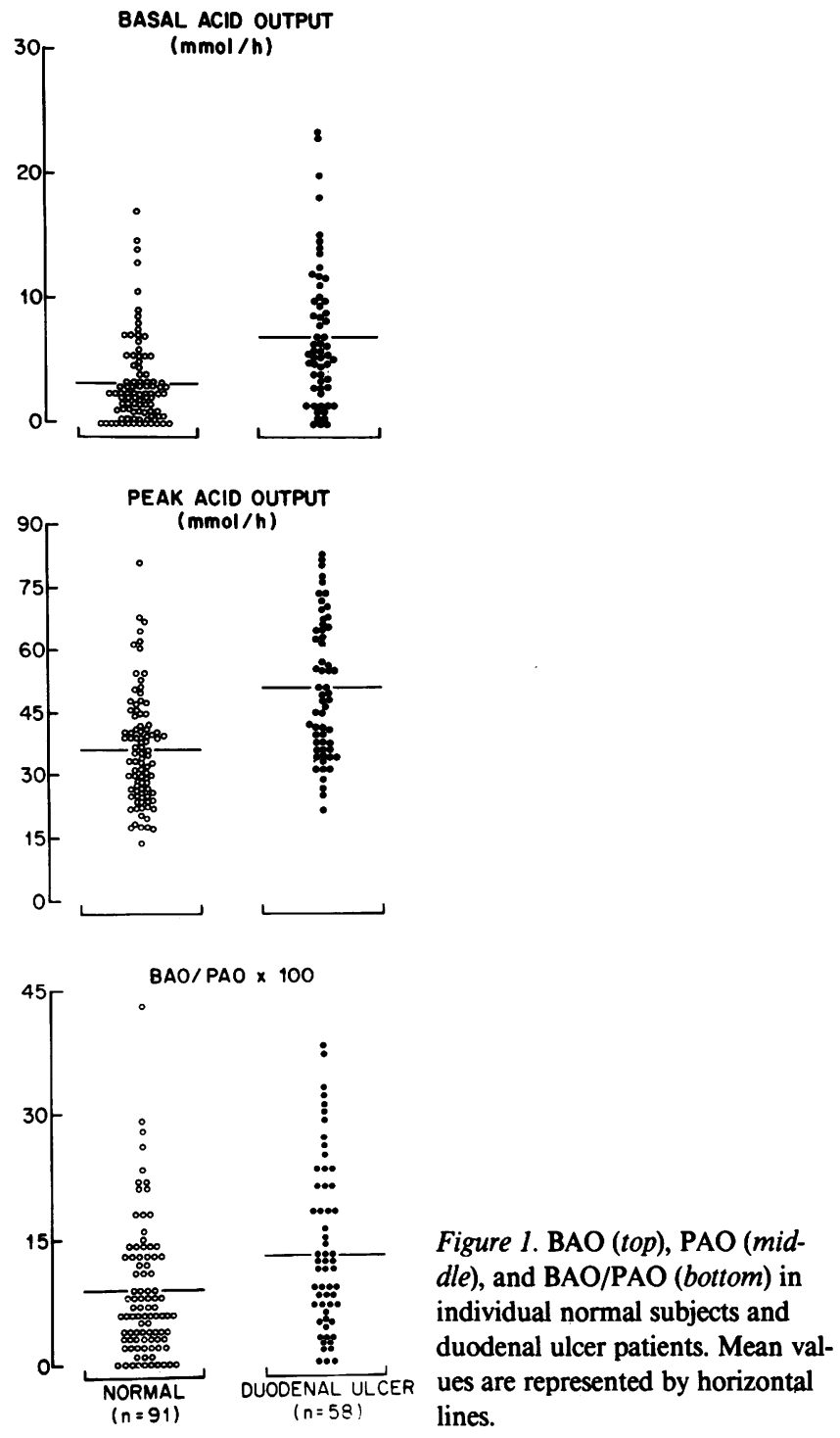

siderable overlap in individual values for BAO, PAO, and BAO/ PAO in the two groups.

\section{Meal-stimulated acid secretion and serum gastrin concentration}

EXPERIMENT 1

Acid secretion. Mean acid secretion after the intragastric meal was only slightly higher in DU patients than normal subjects (Fig. 2, left). Mean acid secretion for the entire 2-h experiment was only $3.4 \mathrm{mmol} / \mathrm{h}$ higher in the DU group (24.3 \pm 1.4 vs. $20.9 \pm 1.1 \mathrm{mmol} / \mathrm{h}, P<0.05)$, probably a reflection of their 3.8 $\mathrm{mmol} / \mathrm{h}$ higher mean BAO. In fact, total basal-subtracted 2-h acid secretory responses to the meal were very similar in individual DU patients and controls (Fig. 3, left). Thus, although DU patients had a much higher maximal secretory capacity (PAO) than controls, they had a similar acid secretory response to the meal. When peak meal-stimulated acid secretion was expressed as a percentage of PAO to pentagastrin or histamine, mean acid secretion was actually lower in DU patients than in normal subjects (Fig. 4, $P<0.002$ ).

Serum gastrin. As shown in Fig. 2 (right), mean basal serum gastrin concentration prior to the intragastric meal was higher in DU patients than normal controls $(49 \pm 4$ vs. $36 \pm 3 \mathrm{pg} / \mathrm{ml}$, 


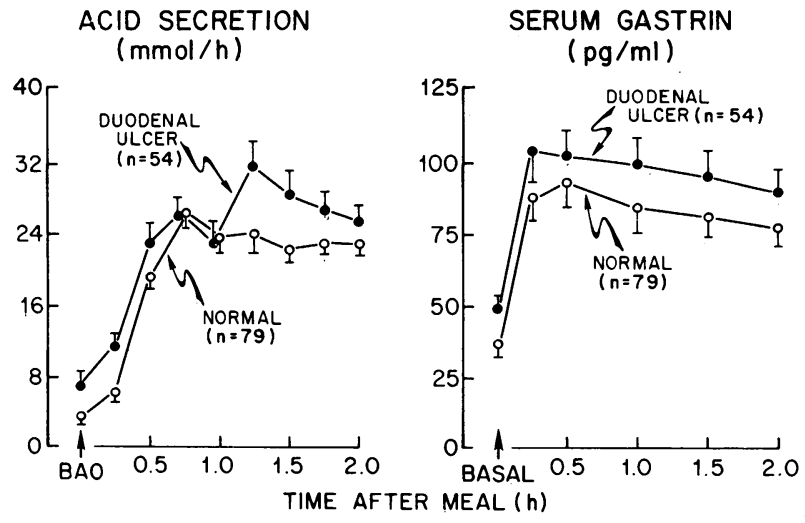

Figure 2. Mean ( $\pm \mathrm{SE})$ acid secretion (left) and serum gastrin concentration (right) in response to intragastric meal infusion in normal subjects and duodenal ulcer patients (experiment 1). BAO is also shown.

$P<0.005)$. Serum gastrin concentration increased by similar amounts in the two groups after the meal. Average serum gastrin rises after the meal were nearly identical in individual DU patients and normal subjects (Fig. 3, right).

\section{EXPERIMENT 2}

Acid secretion. Mean acid secretion was similar in DU patients and normal subjects after the combined intragastric meal-sham feeding experiment (Fig. 5, left). Total, 2-h acid secretion was not significantly different, averaging $32.8 \pm 3.9 \mathrm{mmol} / \mathrm{h}$ in DU patients and $30.8 \pm 2.9 \mathrm{mmol} / \mathrm{h}$ in normal subjects. As in experiment 1 , peak meal-stimulated acid secretion, expressed as a percentage of PAO, was significantly lower in DU patients than in normal subjects $(82 \pm 6$ vs. $113 \pm 7 \%, P<0.001)$.

Serum gastrin. Although mean basal serum gastrin concentration was higher in DU patients than in normal controls $(50 \pm 5$ vs. $28 \pm 4 \mathrm{pg} / \mathrm{ml}, P<0.001$ ), the serum gastrin increase after the combined intragastric meal-sham feeding experiment was similar

\section{BASAL SUBTRACTED ACID SECRETION} $(\mathrm{mmol} / 2 \mathrm{~h})$

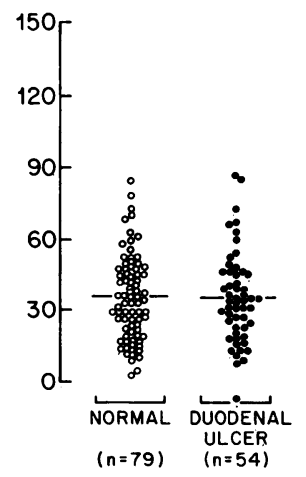

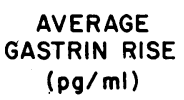

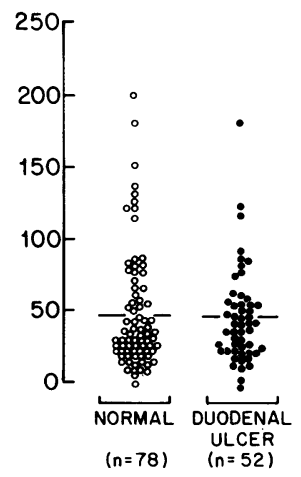

Figure 3. Total 2-h basal-subtracted acid secretion in response to intragastric meal infusion (experiment 1 ) in normal subjects and duodenal ulcer patients (left). Basal-subtracted average serum gastrin rise (calculated by dividing the intergrated gastrin response by $2 \mathrm{~h}$ ) in response to the intragastric meal infusion (experiment 1 ) for each subject and patient (right). Blood samples could not be obtained from one normal subject and two ulcer patients for serum gastrin determination. Mean values are shown as horizontal lines.

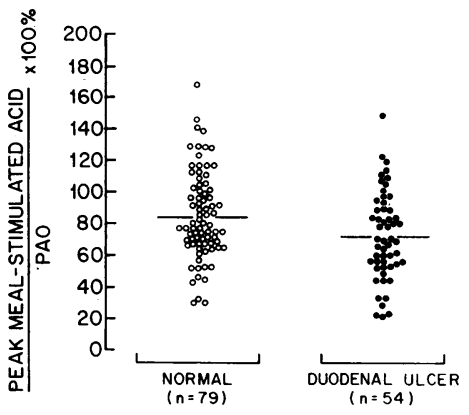

Figure 4. Peak meal-stimulated acid secretion in response to intragastric meal infusion (experiment 1) expressed as a percentage of PAO in normal subjects and duodenal ulcer patients. Peak meal-stimulated acid secretion and PAO were calculated as described in the text. Basal acid output was not sub-

tracted from peak meal-stimulated acid secretion. Mean values are shown as horizontal lines.

in the two groups (Fig. 5, right). Average serum gastrin rises during the experiment were $57 \pm 7 \mathrm{pg} / \mathrm{ml}$ in DU patients and $70 \pm 13 \mathrm{pg} / \mathrm{ml}$ in normal controls $(P>0.05)$.

\section{EXPERIMENT 3}

Acid secretion. In normal subjects, mean acid secretion rates were significantly higher than BAO for the first $4 \mathrm{~h}$ after intragastric meal infusion (Fig. 6, top left). By the fifth postprandial hour, however, acid secretion had returned to the mean basal rate of $3.3 \mathrm{mmol} / \mathrm{h}$ for these 15 normal subjects. In DU patients, on the other hand, mean acid secretion remained significantly higher than BAO for the entire $5 \mathrm{~h}$ period after meal infusion (Fig. 6, bottom left). During the fifth postprandial hour, acid secretion averaged $14.6 \pm 2.9 \mathrm{mmol} / \mathrm{h}(P<0.02$ compared with BAO of $10.9 \pm 2.5 \mathrm{mmol} / \mathrm{h}$ for these $15 \mathrm{DU}$ patients).

Serum gastrin. As shown in Fig. 6 (right), mean basal serum gastrin concentrations prior to the meal were higher in DU patients than in normal subjects $(76 \pm 8$ vs. $52 \pm 8 \mathrm{pg} / \mathrm{ml}, P<0.005)$. However, the pattern of gastrin release over the $5 \mathrm{~h}$ experiment was similar in the two groups. Average serum gastrin rises in response to the meal were not significantly different $(55 \pm 8 \mathrm{pg} /$ $\mathrm{ml}$ for DU patients compared with $64 \pm 11 \mathrm{pg} / \mathrm{ml}$ for normal subjects).

\section{EXPERIMENT 4}

In this experiment the meal was eaten normally and intragastric pH was allowed to seek its natural level. Basal serum gastrin

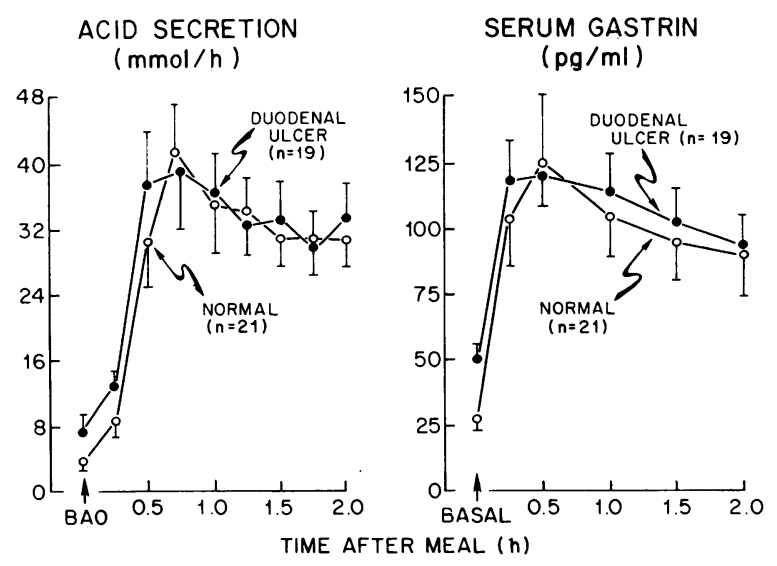

Figure 5. Mean ( $\pm \mathrm{SE})$ acid secretion (left) and serum gastrin concentration (right) in response to sham feeding plus intragastric meal infusion in normal subjects and duodenal ulcer patients (experiment 2). BAO is also shown. 

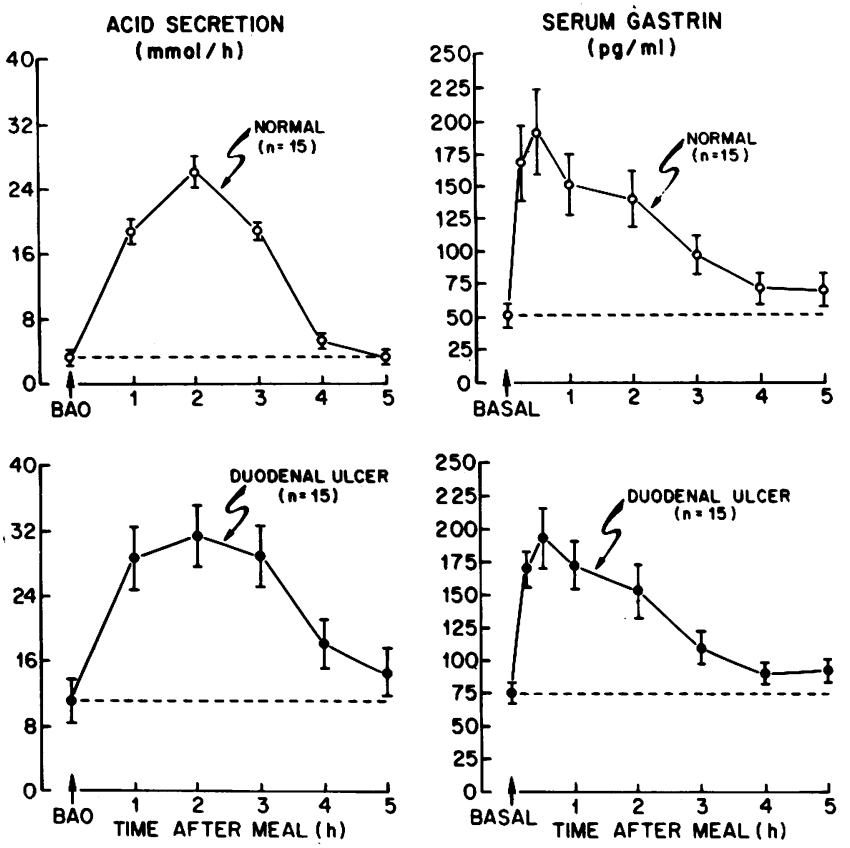

Figure 6. Mean ( $\pm \mathrm{SE}$ ) acid secretion (left) and serum gastrin concentration (right) during 5-h meal experiments (experiment 3 ) in normal subjects (top) and duodenal ulcer patients (bottom). Acid secretion for each hour is plotted at the end of the hour. BAO is also shown. Basal serum gastrin concentrations were averaged and plotted at $0 \mathrm{~min}$.

concentrations before the meal were not significantly different in the two groups (Fig. 7). After the meal, serum gastrin concentrations were slightly but not significantly lower in DU patients, with average serum gastrin rises after the meal of $40 \pm 6$ $\mathrm{pg} / \mathrm{ml}$ in DU patients and $59 \pm 24 \mathrm{pg} / \mathrm{ml}$ in normal subjects $(P$ $>0.05$ ).

\section{Discussion}

Our results confirm that DU patients have increased basal and peak acid outputs $(1,15,16)$. Increased BAO was not simply a manifestation of an increased PAO and parietal cell mass (17, 18 ), inasmuch as the ratio of BAO to PAO was also significantly higher in DU patients than in normal subjects. A higher ratio of BAO to PAO suggests that parietal cells of DU patients are under increased basal secretory drive. Because the parietal cell membrane contains stimulatory receptors for gastrin, acetylcholine, and histamine (19), it seems reasonable to postulate

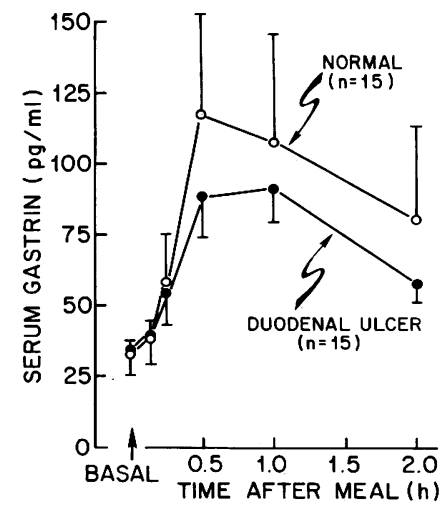

Figure 7. Mean $( \pm \mathrm{SE})$ serum gastrin concentrations in response to a normally eaten meal in normal subjects and duodenal ulcer patients (experiment 4). Basal gastrin concentrations were averaged and plotted at $0 \mathrm{~min}$. that increased release of one or more of these substances under basal conditions, or increased sensitivity to one or more of these substances, may contribute to an increase in BAO and $\mathrm{BAO} /$ PAO in DU patients. With respect to gastrin, some previous studies have found higher basal serum gastrin concentrations in DU patients compared with normal subjects (20-25), whereas others have shown no difference $(9,26-32)$. Many of these previous reports used a relatively small number of patients and controls. In three of our four experiments, including experiment 1 in which we evaluated 54 DU patients and 79 normal subjects, basal serum gastrin concentrations were significantly higher in DU patients than controls and the increase in basal serum gastrin concentration, which ranged from 13 to $26 \mathrm{pg} / \mathrm{ml}$, could have contributed to increased BAO in our DU patients. It is unclear why basal serum gastrin concentrations were similar in the fourth experiment, but this could represent a type II error as a result of a relatively small subject and patient sample size.

Serum gastrin responses to a meal were similar in DU patients and normal subjects, and this was true whether or not sham feeding was carried out in conjunction with intragastric meal infusion and also whether intragastric $\mathrm{pH}$ was kept constant at 5.0 (experiments 1,2 , and 3) or allowed to seek its natural level (experiment 4). Our results agree with several previous reports $(6,7,9,22,31)$, but disagree with others which have reported significantly higher postprandial serum gastrin responses in DU patients $(21,23-25,29,30,32)$. The reason for discrepancies among studies is uncertain, but the numbers of patients and subjects in our studies (especially experiment 1 ) is by far the largest reported to date. In a recent study by Hirschowitz et al. (22), the maximal amount of gastrin released by bombesin was greater in 9 DU patients than in 10 controls, yet, as in our experiments, the DU patients and controls released approximately the same amount of gastrin after a meal.

The gastric acid secretory response to a meal was similar in DU patients and normal subjects, even though the DU patients had a higher maximal acid secretory capacity (PAO). When mealstimulated acid secretion was expressed as a percentage of PAO, in order to correct for differences in secretory capacity among DU patients and normal subjects, acid secretion was actually lower in DU patients than controls. Lower postprandial acid secretion in DU patients, relative to their PAO, is even more remarkable in that these patients started with a significantly higher BAO/PAO than normal subjects.

In 1973, Fordtran and Walsh (3) reported that seven DU patients secreted at a higher percent of their PAO than six normal controls after eating, and their findings were supported by a study by Jalan et al. (4), which included seven DU patients and five controls. These authors suggested that, in addition to a large parietal cell mass, increased parietal cell responsiveness to a meal may be important in the pathogenesis of duodenal ulcer. In two somewhat larger studies, Bodemar et al. (5) and Lam and associates (9) found that meal-stimulated acid secretion was higher in DU patients ( $n=16$ and $n=25$, respectively) compared with controls ( $n=14$ in both), but acid secretion was similar relative to PAO in the two groups, implying equal parietal cell responsiveness. In contrast, Malagelada et al. (6) and Gross and coworkers (7) found that meal-stimulated acid secretion was similar in DU patients and controls despite a significantly higher PAO in the DU group. Thus, in the study by Malagelada et al. (6), which included 12 DU patients and 8 controls, and in the study by Gross et al. (7), which included 10 DU patients and 10 controls, meal-stimulated acid secretion represented a lower fraction 
of PAO in DU patients. In our experiment 1 , which included 54 DU patients and 79 controls, meal-stimulated acid secretion rates were similar in the two groups, and peak meal-stimulated acid secretion averaged $72 \%$ of PAO in DU patients compared with $84 \%$ of PAO in controls (Fig. $4, P<0.002$ ). Furthermore, in experiment 2 in which eating was simulated by combining sham feeding with intragastric meal infusion, acid secretion rates were similar in DU patients and controls, and peak meal-stimulated acid secretion averaged $82 \%$ of PAO in 19 DU patients and $113 \%$ of PAO in 21 controls $(P<0.001)$. Thus, our study, which is much larger than any previous study comparing foodstimulated acid secretion in DU patients and controls, is in close agreement with previous findings of both Malagelada and Gross and their co-workers $(6,7)$.

It is interesting to speculate why our DU patients secreted at a lower than normal fraction of their PAO after a meal. Gastrin is the major stimulant of acid secretion after food $(8,9)$, but for two reasons our results suggest that lower postprandial acid secretion in DU patients (relative to their maximal acid secretory capacity) was independent of gastrin. First, postprandial serum gastrin concentrations were similar in DU patients and controls. Thus, parietal cells of DU patients and normal subjects were exposed to similar circulating gastrin concentrations. Secondly, results of G-17 infusion experiments indicate that, for any given serum gastrin concentration, parietal cells of DU patients and normal subjects secrete at approximately the same percentage of PAO $(22,33)$. Thus, if gastrin were the only factor responsible for food-stimulated acid secretion, one might predict that DU patients and normal subjects would secrete at approximately the same percentage of PAO. To account for our finding that DU patients secreted at a lower fraction of PAO after a meal, it is necessary to postulate that some DU patients either released a deficient quantity of a nongastrin stimulant of acid secretion or, conversely, that, relative to normal controls, some ulcer patients released an inhibitor of acid secretion after a meal.

The major forms of gastrin released into the circulation after a meal are G-17 and G-34 (34). Other minor species of gastrin are also released into the circulation after eating that would not be detected by the C-terminal-directed gastrin antibody we employed. For example, the N-terminal tridecapeptide of G-17, (113)G-17, is released after a meal and Petersen et al. (35) have reported that this peptide inhibits, rather than stimulates, acid secretion. These investigators have also reported that postprandial release of (1-13)G-17 is excessive in DU patients (36). Thus, (1-13)G-17 is one of the candidate substances that may be acting as an inhibitor of meal-stimulated acid secretion in DU patients. However, Pauwels et al. (37) have recently reported that (113)G-17 does not inhibit acid secretion in humans. Further studies will be required to evaluate the role of $(1-13) \mathrm{G}-17$ as well as other possible inhibitors of food-stimulated acid secretion in DU patients.

During experiment 3, when acid secretion was measured for $5 \mathrm{~h}$ after an intragastric meal, DU patients had a somewhat prolonged acid secretory response to the meal, even though during the early postprandial period acid secretion was similar to that of controls. A prolonged postprandial acid secretory response to food in DU patients has been noted previously by Malagelada et al. (6) using an indicator-dilution method to measure acid secretion. It is uncertain why DU patients have prolonged postprandial acid secretion compared to normal individuals. It probably cannot be attributed to gastrin inasmuch the postprandial rise in serum gastrin concentration was similar in both groups during the 5-h period. Delayed emptying of food from the stomach in DU patients could allow prolonged contact of food with gastric mucosa and a prolonged acid secretory response. However, DU patients tend to empty meals more rapidly from the stomach than normal individuals $(1,6)$, making delayed gastric emptying an unlikely explanation for the longer duration of food-stimulated acid secretion in DU patients. Regardless of the mechanism, prolonged postprandial acid secretion, coupled with an elevated BAO, probably explains why DU patients have a higher total 24-h acid secretion rate compared to healthy individuals (38).

Our detailed comparison of acid secretion and gastrin release in DU patients and controls leads to two major conclusions. First, despite generally higher fasting (basal) serum gastrin concentrations, serum gastrin concentrations after a meal increased to the same extent in DU patients and controls. In none of our DU patients did the level of average postprandial gastrin rise exceed the range of average postprandial gastrin in normal individuals. Thus, increased gastrin release in response to a meal is probably a very uncommon pathogenetic factor in duodenal ulcer disease. Secondly, despite higher fasting (basal) acid secretion, DU patients secreted approximately the same amount of acid as did normal subjects after eating, although the acid secretory response to a meal was slightly prolonged in DU patients. That DU patients and normal controls secrete at almost identical rates after a meal is remarkable because the former group has a much larger maximal capacity for acid secretion. Thus, our findings suggest that postprandial acid secretion may be less important in the pathogenesis of duodenal ulcer disease than basal, interprandial, or nocturnal acid secretion.

\section{Acknowledgments}

The authors thank Mary Walker, Julie Oliver, and Kathy Cooper for expert technical assistance, Pat Ladd for illustrations, and Vicky Slagle for manuscript preparation.

This work was supported by grants 16816 and 17294 from the National Institutes of Health, by the Veterans Administration, and by the Berta M. and Cecil O. Patterson Endowment Fund in Digestive Diseases.

\section{References}

1. Soll, A. H., and J. I. Isenberg. 1983. Duodenal ulcer diseases. In Gastrointestinal Disease. 3rd edition. M. H. Sleisenger, and J. S. Fordtran, editors. W. B. Saunders Co., Philadelphia. 625-672.

2. Grossman, M. I. 1978. Abnormalities of acid secretion in patients with duodenal ulcer. Gastroenterology. 75:524-526.

3. Fordtran, J. S., and J. H. Walsh. 1973. Gastric acid secretion rate and buffer content of the stomach after eating: results in normal subjects and in patients with duodenal ulcer. J. Clin. Invest. 52:645-657.

4. Jalan, K. N., D. Mahalanabis, T. K. Maitra, and S. K. Agarwal. 1979. Gastric acid secretion rate and buffer content of the stomach after a rice- and a wheat-based meal in normal subjects and patients with duodenal ulcer. Gut. 20:389-393.

5. Bodemar, G., A. Walan, and G. Lundquist. 1978. Food-stimulated acid secretion measured by intragastric titration with bicarbonate in patients with duodenal and gastric ulcer disease and in controls. Scand. J. Gastroenterol. 13:911-918.

6. Malagelada, J.-R., G. F. Longstreth, T. B. Deering, W. H. J. Summerskill, and V. L. W. Go. 1977. Gastric secretion and emptying after ordinary meals in duodenal ulcer. Gastroenterology. 73:989-994.

7. Gross, R. A., J. I. Isenberg, D. Hogan, and I. M. Samloff. 1978. Effect of fat on meal-stimulated duodenal acid load, duodenal pepsin load, and serum gastrin in duodenal ulcer and normal subjects. Gastroenterology. 75:357-362. 
8. Feldman, M., J. H. Walsh, H. C. Wong, and C. T. Richardson. 1978. Role of gastrin heptadecapeptide in the acid secretory response to amino acids in man. J. Clin. Invest. 61:308-313.

9. Lam, S. K., J. I. Isenberg, M. I. Grossman, W. H. Lane, and J. H. Walsh. 1980. Gastric acid secretion is abnormally sensitive to endogenous gastrin released after peptone test meals in duodenal ulcer patients. J. Clin. Invest. 65:555-562.

10. Feldman, M., and C. T. Richardson. 1981. Gastric acid secretion in humans. In Physiology of the Gastrointestinal Tract. L. R. Johnson, editor. Raven Press, New York. 693-707.

11. Moore, E. W., and R. W. Scarlata. 1965. The determination of gastric acidity by the glass electrode. Gastroenterology. 49:178-188.

12. Richardson, C. T., J. H. Walsh, K. A. Cooper, M. Feldman, and J. S. Fordtran. 1977. Studies on the role of cephalic-vagal stimulation in the acid secretory response to eating in normal human subjects. $J$. Clin. Invest. 60:435-441.

13. Eysselein, V. E., V. Maxwell, T. Reedy, E. Wunsch, and J. H. Walsh. 1984. Similar acid stimulatory potencies of synthetic human big and little gastrins in man. J. Clin. Invest. 73:1284-1290.

14. Schiller, L. R., J. H. Walsh, and M. Feldman. 1982. Effect of atropine on gastrin release stimulated by an amino acid meal in humans. Gastroenterology. 83:267-272.

15. Baron, J. H. 1979. Clinical Tests of Gastric Secretion: History, Methodology and Interpretation. Oxford University Press, New York.

16. Wormsley, K. G., and M. I. Grossman. 1965. Maximal histalog test in control subjects and patients with peptic ulcer. Gut. 6:427-435.

17. Cox, A. J. 1952. Stomach size and its relation to chronic peptic ulcer. AMA (Am. Med. Assoc.) Arch. Pathol. 54:407-422.

18. Card, W. I., and I. N. Marks. 1960. The relationship between the acid output of the stomach following "maximal" histamine stimulation and the parietal cell mass. Clin. Sci. (Lond.). 19:147-163.

19. Soll, A. H., D. A. Amirian, L. P. Thomas, T. J. Reedy, and J. D. Elashoff. 1984. Gastrin receptors on isolated canine parietal cells. J. Clin. Invest. 73:1434-1447.

20. Berson, S. A., J. H. Walsh, and R. S. Yalow. 1970. Radioimmunoassay of gastrin in human plasma and regulation of gastrin secretion. In Symposium on Frontiers in Gastrointestinal Research (Special Nobel Symposia Series). Almqvist and Wiksell, Uppsala, Sweden. 57-66.

21. Byrnes, D. J., J. D. Young, D. J. Chisholm, and L. Lazarus. 1970. Serum gastrin in patients with peptic ulceration. Br. Med. J. 2:625-629.

22. Hirschowitz, B. I., L. O. Tim, C. A. Helman, and E. Molina 1985. Bombesin and G-17 dose responses in duodenal ulcer and controls. Dig. Dis. Sci. 30:1092-1103.

23. Reeder, D. D., B. M. Jackson, J. L. Ban, W. D. Davidson, and J. C. Thompson. 1970. Effect of food on serum gastrin concentrations in duodenal ulcer and control patients. Surg. Forum. 21:290-291.

24. Becker, H. D., D. D. Reeder, and J. C. Thompson. 1973. Effect of truncal vagotomy with pyloroplasty or with antrectomy on food-stim- ulated gastrin values in patients with duodenal ulcer. Surgery. 74:580586.

25. Mayer, G., R. Arnold, G. Feurle, K. Fuchs, H. Ketterer, N. S. Track, and W. Creutzfeldt. 1974. Influence of feeding and sham feeding upon serum gastrin and gastric acid secretion in control subjects and duodenal ulcer patients. Scand. J. Gastroenterol. 9:703-710.

26. Korman, M. G., C. Soveny, and J. Hansky. 1971. Serum gastrin in duodenal ulcer. Gut. 12:899-902.

27. Trudeau, W. L., and J. E. McGuigan. 1971. Relations between serum gastrin levels and rates of gastric hydrochloric acid secretion. $N$. Engl. J. Med. 284:408-412.

28. Ganguli, P. C., and W. M. Hunter. 1972. Radio-immunoassay of gastrin in human plasma. J. Physiol. (Lond.). 220:499-510.

29. McGuigan, J. E., and W. L. Trudeau. 1973. Differences in rates of gastrin release in normal persons and patients with duodenal-ulcer disease. $N$. Engl. J. Med. 288:64-66.

30. Taylor, I. L., G. J. Dockray, J. Calam, and R. J. Walker. 1979. Big and little gastrin responses to food in normal and ulcer subjects. Gut. 20:957-962.

31. Hughes, W. S., and A. J. Hernandez. 1976. Antral gastrin concentration in patients with vagotomy and pyloroplasty. Gastroenterology. 71:720-722.

32. Nyren, O., H.-O. Adami, R. Bergstrom, S. Gustavsson, L. Loof, and G. Lundqvist. 1986. Basal and food-stimulated levels of gastrin and pancreatic polypeptide in non-ulcer dyspepsia and duodenal ulcer. Scand. J. Gastroenterol. 21:471-477.

33. Blair, A. J., C. T. Richardson, M. Vasko, J. H. Walsh, and M. Feldman. 1986. Comparison of acid secretory responsiveness to gastrin heptadecapeptide and of gastrin heptadecapeptide pharmacokinetics in duodenal ulcer patients and normal subjects. J. Clin. Invest. 78:779783.

34. Dockray, G. J., and I. L. Taylor. 1976. Heptadecapeptide gastrin measurement in blood by specific radioimmunoassay. Gastroenterology. 71:971-977.

35. Petersen, B., J. Christiansen, and J. F. Rehfeld. 1983. The Nterminal tridecapeptide fragment of gastrin-17 inhibits gastric acid secretion. Regul. Pept. 7:323-334.

36. Petersen, B., and J. F. Rehfeld. 1980. The $\mathrm{NH}_{2}$-terminal tridecapeptide fragment of gastrin-17 in serum from duodenal ulcer patients. Scand. J. Gastroenterol. 15:29-31.

37. Pauwels, S., G. J. Dockray, R. Walker, and S. Marcus. 1985. Metabolism of the 1-13 sequence of gastrin 17 in humans and failure to influence acid secretion. Gastroenterology. 89:49-56.

38. Feldman, M., and C. T. Richardson. 1986. Total 24-hour gastric acid secretion in patients with duodenal ulcer: comparison with normal subjects and effects of cimetidine and parietal cell vagotomy. Gastroenterology. 90:540-544. 